\section{Kinetics of dimethoate biodegradation in bacterial system}

\author{
Manisha DebMandal, ${ }^{1}$ \\ Shyamapada Mandal, ${ }^{2}$ \\ Nishith Kumar Pal ${ }^{3}$
}

1Department of Physiology and

Biophysics, KPC Medical College

and Hospital, Jadavpur, ${ }^{2}$ Department of

Zoology, Gurudas College, Narkeldanga,

${ }^{3}$ Department of Microbiology, Institute

of Post Graduate Medical Education and

Research, Kolkata, India

\section{Abstract}

The present study is an investigation on the kinetics of dimethoate biodegradation and an estimation of residual dimethoate in bacterial culture by spectrophotometry. The methylene chloride extract of the culture medium was used for determination of dimethoate through its reaction with 1 chloro- 2,4 dinitrobenzene to produce methylamine whose absorbance at $505 \mathrm{~nm}$ gave an estimation of dimethoate content. The dimethoate standard curve follows Beer's law at $505 \mathrm{~nm}$ with a slope of 0.0129 absorbance units per $\mu \mathrm{g} / \mathrm{mL}$. The regression equation relating concentration of dimethoate (x) with the absorbance is (y): $y=0.037+$ $0.0129 x$. The amount of residual dimethoate after 7 days were $0,4,17,28$ and $29 \mu \mathrm{g} / \mathrm{mL}$; the rate constants were $0.775,0.305,0.225,0.167$ and 0.127 each per day, and the efficiency of dimethoate degradation were $100 \%, 96 \%, 83 \%$, $72 \%$ and $71 \%$, for Bacillus licheniformis, Pseudomonas aeruginosa, Aeromonas hydrophila, Proteus mirabilis and Bacillus pumilus respectively. Dimethoate remediation could be attained through bacterial metabolism of the pesticide and colorimetric analysis might be useful in the estimation of dimethoate within a detection limit of 5-100 $\mu \mathrm{g} / \mathrm{mL}$.

\section{Introduction}

Organophosphorus compounds such as dimethoate [0, 0-dimethyl S-methyl-carbamoyl-methyl phosphorodithioate], has both plant and animal systemic insecticidal properties $^{1}$ and constitutes the largest class of insecticide used worldwide. ${ }^{2}$ It is nerve toxin, carcinogen, teratogen, has high oral and dermal acute toxicity, is an eye irritant, and is readily absorbed through lungs. In view of its toxicity, it is important to remove dimethoate from the environment. Naturally occurring microorganisms have a physiological versatility and catabolic potential to degrade a large number of organic or synthetic compounds.-5 Bacterial species can utilize an insecticide as a sole source of carbon and energy for growth, which is manifested by consumption of the parent compound, and which can be detected and estimated by various methods. ${ }^{2,3,5,6}$ Several methods for the determination of dimethoate compound have been reviewed based on column, paper, and thin layer chromatography, paper electrophoresis, colorimetry, gas chromatography, and radiometry, tandem mass spectrometry. $2,3,7,8$ The toxicity of dimethoate in freshwater airbreathing catfish Heteropneustes fossilis was carried out by bioassay method. ${ }^{9}$ The investigations, reported herein, were undertaken for the quantitative estimation of dimethoate when it was introduced directly as a sole source of carbon and energy in bacterial system; another aspect of this investigation was to study the dynamics of dimethoate biodegradation using bacterial isolates from different sources.

\section{Materials and Methods}

\section{Bacterial strain}

Five bacterial strains, namely, Bacillus licheniformis (B. licheniformis) F102, Pseudomonas aeruginosa (Ps. aeruginosa) W171, Aeromonas hydrophila (A. hydrophila) 0102, Bacillus pumilus (B. pumilus) KS23 and Proteus mirabilis (P. mirabilis) C114 isolated, respectively from the intestine of Labeo rohita, Ganges river water, intestine of Clarius batracus, soil sample and urinary tract infection case, were taken for the present study. All the strains are capable of tolerating high amount of dimethoate in nutrient agar medium. ${ }^{10}$

\section{Culture condition}

The bacterial strains were grown in $50 \mathrm{~mL}$ Mineral salts (MS) solution ${ }^{11}$ containing 100 $\mu \mathrm{g} / \mathrm{mL}$ of dimethoate as the sole source of carbon at $28^{\circ} \mathrm{C}$ for $24 \mathrm{~h}$. From this culture, bacterial inoculum amounting to approximately $5 \times$ $10^{5} \mathrm{CFU} / \mathrm{mL}$ was prepared as described earli$\mathrm{er}^{10}$ for all the strains. In separate conical flasks containing $100 \mathrm{~mL}$ MS solution supplemented with $100 \mu \mathrm{g} / \mathrm{mL}$ of dimethoate, was inoculated $0.1 \mathrm{~mL}$ of the bacterial inoculum of $5 \times 10^{5} \mathrm{CFU} / \mathrm{mL}$ and incubated at $28^{\circ} \mathrm{C}$ for up to seven days.

\section{Methylene chloride extract of dimethoate}

An aliquot of $1 \mathrm{~mL}$ of the bacterial culture
Correspondence: Shyamapada Mandal, Department of Zoology, Gurudas College, Narkeldanga, Kolkata-700 054, India.

E-mail: samtropmed@gmail.com

Key words: Dimethoate, degradation kinetics, bacteria cultures, colorimetric estimation.

Contributions: MDM, designed the study, did experimental work, data analysis and manuscript preparation; SM did experimental work, data analysis and manuscript preparation; NKP, data analysis and manuscript preparation.

Conflict of interest: the authors report no conflicts of interest.

Received for publication: 4 August 2011 Accepted for publication: 23 October 2011.

This work is licensed under a Creative Commons Attribution NonCommercial 3.0 License (CC BYNC 3.0).

(C) Copyright M. DebMandal et al., 2011

Licensee PAGEPress, Italy

Microbiology Research 2011; 2:e20

doi:10.4081/mr.2011.e20

fluid cells were taken out aseptically from 100 $\mathrm{mL}$ stock culture after every $24 \mathrm{~h}$ for up to 7 days and treated as described for the preparation of acetonitrile extract. ${ }^{11}$ The cells were removed from the culture by centrifugation at $4000 \times \mathrm{g}$ for $20 \mathrm{~min}$. The supernatant was extracted twice with equal volumes of methylene chloride, shaken vigorously and centrifuged at $4000 \times \mathrm{g}$ and the organic fraction was transferred to a separate tube. The methylene chloride extract was used for the estimation of unknown amount of dimethoate.

\section{Preparation of $99 \%$ dimethoate}

The dimethoate (95\% purity), obtained from Rallis India Limited, Bangalore, India, was purified to $99 \%$, as described earlier by DebMandal et al. ${ }^{11}$

\section{Preparation of standard curve}

The standard curve for dimethoate was prepared, as has been described earlier. ${ }^{12} \mathrm{~A}$ range of dimethoate solutions containing 0 to 100 $\mu \mathrm{g} / \mathrm{mL}$ of $99 \%$ dimethoate was prepared in methylene chloride in a series of glass-stoppered test tubes. One drop of $0.5 \%$ lanolin solution was added to each tube to prevent loss during the evaporation. The solvent was evaporated in a $70^{\circ} \mathrm{C}$ water bath. The dimethoate present in each test tube was hydrolyzed with $1 \mathrm{~mL}$ of $0.5 \mathrm{~N}$ methanolic sodium hydroxide solution followed by heating for $10 \mathrm{~min}$ in a water bath pre-adjusted to $60^{\circ} \mathrm{C}$. The resulting reaction mixture was immediately cooled in a cold-water bath. To each of the tubes, $0.1 \mathrm{~mL}$ of the 1-chloro 2, 4 dinitrobenzene reagent was 
added, stoppered and shaken for 10 min. Next, $2 \mathrm{~mL}$ of absolute ethyl alcohol was added and swirled. The absorbance of the resulting red colored solution was measured in spectrophotometer at $505 \mathrm{~nm}$. Absolute ethyl alcohol was taken as the blank solution and the standard curve was prepared by plotting the absorbance reading against micrograms of dimethoate.

\section{Colorimetric estimation of residual dimethoate from bacterial cultures}

Each of the bacterial culture taken at regular interval of day $1,2,3,4,5,6$, and 7 was extracted as described above with methylene chloride and dimethoate in the culture was treated with methanolic sodium hydroxide and 1 chloro-2, 4 dinitrobenzene to form the red colored compound, whose absorbance was measured at $505 \mathrm{~nm}$. The unknown amount of residual dimethoate present due to biodegradation was determined from the standard dimethoate curve. ${ }^{12}$

\section{Biodegradation dynamics}

The dynamics of dimethoate biodegradation in liquid culture, of bacterial strains, $B$. licheniformis F102, Ps. aeruginosa W171, A. hydrophila 0102, B. pumilus KS23, and Pr. mirabilis $\mathrm{C114}$ was examined at an initial concentration of $100 \mu \mathrm{g} / \mathrm{mL}$ dimethoate, after a period of seven days. ${ }^{12}$ The efficiency of dimethoate degradation was evaluated with respect to their percent biodegradation, rate constants, and half-lives for dimethoate degradation.

\section{Results}

The dimethoate standard curve follows Beer's law at $505 \mathrm{~nm}$, in the range of 5-100 $\mu \mathrm{g} / \mathrm{mL}$ of dimethoate, and it has a slope of 0.0129 absorbance units per $\mu \mathrm{g} / \mathrm{mL}$. The blank solution (absolute ethyl alcohol) gives an average absorbance of 0.034 . The regression equation relating concentration of dimethoate $(\mathrm{x})$ with the absorbance is (y): $y=0.037+$ $0.0129 x$. Herein it was found that $1 \mu \mathrm{g} / \mathrm{mL}$ dimethoate was equivalent to an absorbance of 0.0142 (Figure 1).

A comparative study of $\ln \left(\mathrm{N}_{0} / \mathrm{N}\right)$ against time in days for the five bacterial isolates, $P$ s. aeruginosa W171, B. licheniformis F102, Pr. mirabilis $\mathrm{C} 114$ strain, B. pumilus KS23 and $A$. hydrophila 0102 strains, at day 1, 2, 3, 4, 5, 6, and 7 is depicted in Figure 2, where $\mathrm{N}_{0}$ is the initial concentration of dimethoate and $\mathrm{N}$ is the dimethoate left at the end of $24 \mathrm{~h}$ incubation period. Residual dimethoate left after bacterial degradation of $100 \mu \mathrm{g} / \mathrm{mL}$ of dimethoate in the liquid culture of $B$. licheniformis F102 culture was $2 \mu \mathrm{g} / \mathrm{mL}$ at day 3 , after which peri- od no residual dimethoate was found. In cultures of the other four dimethoate degraders: Ps. aeruginosa W171, A. hydrophila 0102, P. mirabilis $\mathrm{C} 114$ and $B$. pumilus $\mathrm{KS} 23$, the residual dimethoate obtained after day 7 were 4,17 , 28 and $29 \mu \mathrm{g} / \mathrm{mL}$ (Figure 2).

The percentage biodegradation of dimethoate in liquid culture for the above five strains after 7 days is presented in Figure 3. The B. licheniformis F102 strain demonstrated $100 \%$ dimethoate degradation at day four. After incubation for 7 day, the rates of degradation of dimethoate were $96 \%, 83 \%, 72 \%$, and $71 \%$ respectively for Ps. aeruginosa W171, A. hydrophila 0102, Pr. mirabilis $\mathrm{C114}$, and $B$. pumilus KS23.

The rate constants $(\lambda)$ for dimethoate using B. licheniformis F102, Ps. aeruginosa W171, A. hydrophila 0102, P. mirabilis $\mathrm{C} 114$ and $B$. pumilus KS23 strains were estimated to be $0.775,0.305,0.225,0.167$ and 0.127 per day each, respectively (Figure 4). The half-lives $\left(\mathrm{T}_{1 / 2}\right)$ for dimethoate were estimated to be $0.894,2.268,3.072,4.135$ and 5.456 days for F102, W171, 0102, C114 and KS23 strains, respectively (Figure 4); no abiotic decrease in dimethoate concentration in control flasks over a seven-day incubation period was observed.

\section{Discussion}

Biological remediation strategies are environmentally desirable, and considered a costeffective option. In the present study, we have demonstrated the removal of dimethoate (at $100 \mu \mathrm{g} / \mathrm{mL}$ ) in enrichment cultures using five different bacterial strains. Several authors have reported on the quantitative determination of dimethoate compound. Pandey et al. ${ }^{9}$ used bioassay method to determine the toxicity of dimethoate in catfish Heteropneustes fossilis and found out the $\mathrm{LC}_{50}$ values for dimethoate to be $2.98-3.38 \mathrm{mg} / \mathrm{L}$ for upto 4 days. Pagliuca et al. ${ }^{1}$ reported that 37 among 135 raw milk samples were positive for traces, and 10 samples showed organophosphorus pesticide contamination in a range $5-18 \mu \mathrm{g} / \mathrm{kg}$. Xiang et al. ${ }^{3}$ monitored dimethoate utilization by Ps. aeruginosa using SPQC (series piezoelectric quartz crystal) and HPLC (high performance liquid chromatography) with determination limit of $1.08 \mathrm{ng}$ in HPLC. Hadjidemetriou et al. ${ }^{13}$ studied the dissipation of dimethoate in citrus foliage by gas-liquid chromatography using $5 \%$ OV-101 coated on a Carbowax 20M surface-modified support (Ultra-Bond 20M). Gamón et al. ${ }^{8}$ quantified pesticides in fruit and vegetables using gas chromatography/tandem mass spectrometry by spectral confirmation of the matrixes after

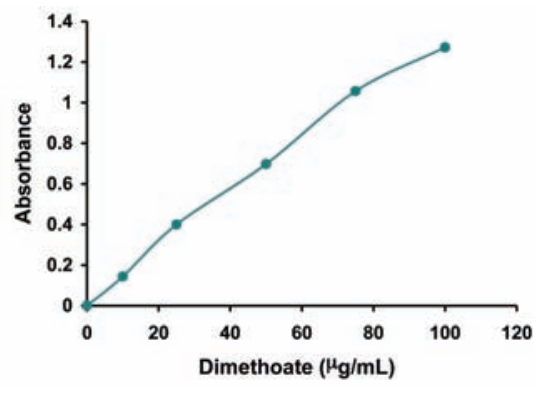

Figure 1. Standard curve for the estimation of dimethoate at $505 \mathrm{~nm}$. The regression equation is $\mathrm{y}=0.037+0.0129 x$.

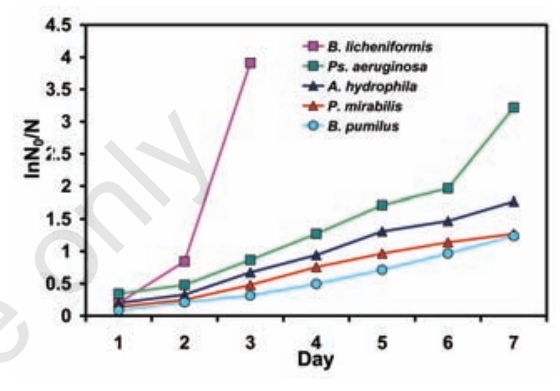

Figure 2. Comparative study of $\ln (\mathrm{NO} / \mathrm{N})$ with time in days for the five bacterial isolates, where $\mathrm{N}_{0}$ is the initial concentration of dimethoate and $\mathrm{N}$ is the dimethoate left at the end of $24 \mathrm{~h}$ incubation period.

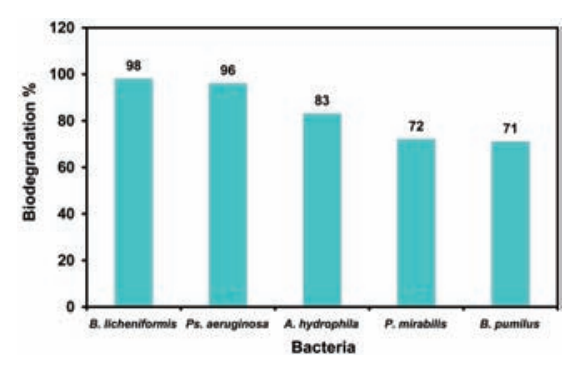

Figure 3. Percent biodegradation of dimethoate by five bacterial isolates.

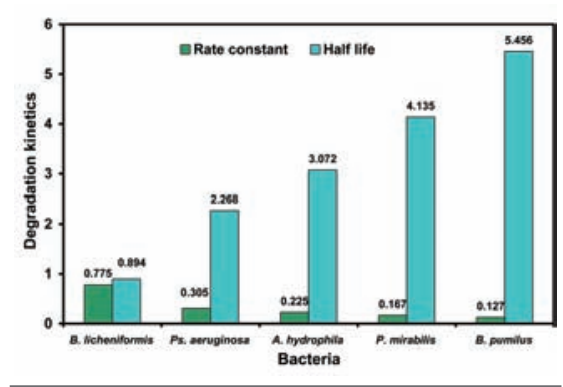

Figure 4. Kinetics, expressed as rate constant (per $24 \mathrm{~h}$ ) and half life (day), of dimethoate degradation reaction using the bacterial isolates. 
extracting the residues from samples with acetone followed by a mixture of dichloromethane-petroleum ether. Szymczyk and Malczewska ${ }^{13}$ presented a GC method for the determination of six organophosphorous pesticide residues including dimethoate in cabbage, in which the chopped cabbage was blended with acetone, extracted with n-hexane:methylene chloride (1:1) mixture. The extract was then purified on a GC column and eluted with the mixture of methylene chloride:cyclohexane (1:1) at the flow rate of 0.5 $\mathrm{mL} / \mathrm{min}$. Dimethoate was extracted from hexane solution with $\mathrm{HBr}$ followed by hydrolysis and determination of the evolved hydrogen sulphide from dimethyl sulphate, as methylene blue. Herein, the parent compound dimethoate was extracted with methylene chloride, followed by alkaline hydrolysis, and colorimetric determination of the resultant methylamine by reaction with 1-chloro-2, 4-dinitrobenzene. Both dimethoate and omethoate react to form the color by the dinitrochlorobenzene colorimetric procedure, but omethoate cannot be determined in the same sample, because gradually it tends to get lost in the clean up procedure.

The B. licheniformis F102 strain isolated from fish intestine degraded $100 \%$ of dimethoate in liquid culture at day four. The rate constant of dimethoate degradation was 0.775 per day for the F102 strain, and half-life of dimethoate was calculated as 0.894 day when the strain was incubated in liquid media. Another bacillus, B. pumilus KS23 strain, a soil bacterium, exerted $71 \%$ degradation of dimethoate at day 7 with a rate constant 0.127 per day, and for this strain half-life of dimethoate was 5.456 days. The water bacteria $P$ s. aeruginosa W171 strain demonstrated an efficiency of degrading $96 \%$ dimethoate at day 7 with rate constant 0.305 per day, and a 2.268 days half-life of dimethoate as was calculated for this strain. For other two strains, $P$. mirabilis $\mathrm{C} 114$ and A. hydrophila 0102, that showed the efficiency of degrading respectively $72 \%$ and $83 \%$ of dimethoate, the respective rate constants was calculated as 0.167 and 0.225 per day, with half-life of dimethoate as 4.135 days and 3.072 days, respectively.

Deshpande et al. ${ }^{14}$ found that $P$ s. aeruginosa and B. megaterium demonstrated an efficiency of more than $95 \%$ for dimethoate degradation after 8 days of incubation, and for the other strains used in their study, the efficiency of dimethoate degradation ranged between $64 \%$ and $90 \%$. Liang et al. ${ }^{4}$ showed that a Raoultella sp. was able to remove up to $75 \%$ of dimethoate via co-metabolism through optimization of carbon and energy source using response surface methodology. Okeke et al., ${ }^{15}$ using Pandoraea sp., reported that after 8 weeks of incubation, 89.9\% and $93.3 \%$ degradation were achieved with $\gamma$ and $\alpha$ hexachlorohexane (150 $\mu \mathrm{g} / \mathrm{mL}$ for each) isomers, respectively. The rate constants for $\gamma$ and $\alpha$ hexachlorohexane, were 0.28 and 0.32 , respectively, and the half-lives were 2.51 weeks and 2 weeks, respectively. Kanrar et al. ${ }^{16}$ determined the dissipation pattern, residue level and half live values of imidacloprid in soil, water, plant, grain husk and straw samples in rice ecosystem. Schmalko et al. ${ }^{17}$ studied degradation kinetics of dimethoate in yerba mate plants by capillary gas chromatography technique. Half-life times in plants ranked between 9.8 and 11.8 days and the dimethoate concentration decayed to a $22.7 \%$ of its initial value (in dry basis); while during seasoning step (at $45^{\circ} \mathrm{C}$ ), half-life time was 17.3 days. Bo and Xin-Huai ${ }^{18}$ found out that the half life periods of dimethoate and other organophosphates were in a range of 4.0 to $10.3 \mathrm{~h}$, at $63^{\circ} \mathrm{C}-100^{\circ} \mathrm{C}$; and that lactic bacteria in Rhodia and Danisco starter cultures increased the degradation of dimethoate in bovine milk to $11.7 \%$ and $20.4 \%$ respectively. Hui-mei ${ }^{1}$ et al. ${ }^{19}$ determined the half-lives of dimethoate in cabbage and soil to be 2 and 1.5 days respectively, through $\mathrm{GC}$ detection, with $90.25-110.39 \%$ recovery and a variation coefficient of $1.51-5.83 \%$. Hadjidemetriou et al. ${ }^{13}$ showed that dimethoate residues were best characterised by two first-order kinetic processes; the half-life values of dimethoate were 2.2 days for the 1-10 days portion, and 7.0 days for the 10-49 days portion.

In this communication, it has been established for the first time that the colorimetric estimation is useful in detecting dimethoate (within a limit of $5-100 \mu \mathrm{g} / \mathrm{mL}$ ) in bacterial system, in order to study the dynamics of the pesticide (dimethoate) biodegradation.

\section{References}

1. Pagliuca G, Serraino A, Gazzotti T et al. Organophosphorus pesticides residues in Italian raw milk. J Dairy Res 2006;73:340-4.

2. International Programme on Chemical Safety, WHO, Geneva. Dimethoate EHC 90. Available from http//www.inchem.org/documents/ehc/ehc/ehc90.htm.

3. Xiang H, Wanzhi W, Biyu T, Xiaotao L. Novel Reduction Kinetics Model of Dimethoate (DMA) on the Growth of Pseudomonas aeruginosa. Anal Lett 2009;42:461-72.

4. Liang Y, Fuhua Z, Guanzhou Q et al. Co-metabolic degradation of dimethoate by Raoultella sp. X1. Earth Environ Sc 2008;20:363-73.

5. Hayatsu M, Hirano M, Tokuda S. Involvement of two plasmids in fenitrothion degradation by Burkhelderia sp. Strain NF100. Appl Environ Microbiol 2000;66:1737-40.

6. DebMandal M, Mandal S, Pal NK. Plasmid mediated dimethoate degradation by Bacillus licheniformis isolated from a fresh water fish
Labeo rohita. J Biomed Biotech 2005;3:280-6.

7. Kumar R. Simultaneous determination of some organophosphorus pesticides by high performance liquid chromatography. Biomed Chromatography 2005;3:272-3.

8. Gamon M, Lleo C, Ten A, Mocholi F. Multiresidue determination of pesticides in fruit and vegetables by gas chromatography/tandem mass spectrometry. JAOAC 2001;84:1209-16.

9. Pandey RK, Singh RN, Singh S et al. Acute toxicity bioassay of dimethoate on freshwater airbreathing catfish, Heteropneustes fossilis (Bloch). J Environ Biol 2009;30:437-40.

10. DebMandal M, Mandal S, Pal NK. Plasmidencoded enzymatic degradation of dimethoate. World J Microbiol Biotech 2008;24:2587-91.

11. DebMandal M, Mandal S, Pal NK, Aich A. Potential metabolites of dimethoate produced by bacterial degradation. World $\mathrm{J}$ Microbiol Biotech 2008;24:69-72.

12. DebMandal M. Experiments on exploration of environmental bacteria degrading a pesticide used in agriculture. Thesis, University of Jadavpur, 2005.

13. Hadjidemetriou DG, Iwata Y, Gunther FA. Analysis and dissipation of dislodgable residues of acephate, dimethoate and formetanate hydrochloride on citrus foliage. Pest Management Sci doi: 10.1002/ps.2780160313, 2006.

14. Deshpande NM, Dhakephalkar PK, Kanekar PP. Plasmid-mediated dimethoate degradation in Pseudomonas aeruginosa MCMB427. Lett Appl Microbiol 2001;33:275-9.

15. Okeke B, Siddique T, Arbestain MC, Frankenberger WT. Biodegradation of gamma- hexachlorocyclohexane (Lindane) and alpha- hexachlorocyclohexane in water and soil slurry by Pandoraea species. J Agric Food Chem 2002;50:2548-55.

16. Kanrar B, Ghosh T, Pramanik SK et al. Degradation dynamics and persistence of imidacloprid in a rice ecosystem under West Bengal climatic conditions. Bull Environ Contamin Toxicol 2006;77:631-7.

17. Schmalko ME, Ramallo LA, Ferreira D, Berlingheri RD. Dimethoate degradation in plants and during processing of yerba maté leaves. Brazilian Arch Biol Technol 2002;45:419-22.

18. Bo LY, Zhao X. Preliminary study on the degradation of seven organophosphorus pesticides in bovine milk during lactic acid fermentation or heat treatment. African $\mathrm{J}$ Microbiol Res 2010;4:1171-9.

19. Hui-meil J, Huil S, Huang-hui $G$ et al. Residues and degradation dynamics of dimethoate $40 \%$ EC in cabbage and soils. 2007. Available form: http://en.cnki.com.cn/Article_en/CJFDTOTAL-NYZZ200704013.htm 